\title{
Early treatment of symphysis mandibular fracture in 12 years old children using erich arch bar: a case report
}

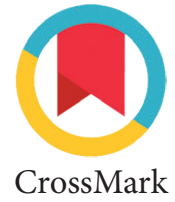

\author{
Syahril Samad, Winarno Priyanto
}

\section{Abstract}

Objective: To explain the management of symphysis mandibular fracture in pediatric using erich arch bar.

Methods: A12years old boyhasfractureinmandible due to the accident occurred when his chin hit the touching motorcycle tank. Clinically a deformity at the anterior of mandible and malocclusion has occurred. Patient also complained a pain with swelling and bleeding at the region of fracture and lip. Suturing had been done in wound area for both intra and extra oral area followed by the application of arch bar in maxilla and mandible. Doing evaluation at the third day, a vague fracture line was found in panoramic radiograph.

Results: The following treatment done was the application of erich arch bar for mobility reducing the fracture of mandibular symphysis. A good healing act management to symphysis mandibular fracture of 12 years old children with full eruption of teeth has been given to the teeth to develop retention and to stabilize the erich arch bar.

Conclusion: Management of pediatric symphysis mandibular fracture for 12 years old children with full eruption of teeth using erich bar revealed a healed fracture.
Department of Oral and Maxillofacial Surgery, Padjadjaran University, Bandung Indonesia
*Correspondence to: Syahril Samad, Department of Oral and Maxillofacial Surgery, Padjadjaran University, Bandung Indonesia arielkazhimdelshadi@gmail.com

Received 23 August 2016

Revised 29 August 2016 Accepted 03 January 2017 Available online 01 April 2017

Keywords: Symphysis mandibular fracture, Erich arch bar

Cite this Article: Samad S, Priyanto W. 2017. Early treatment of symphysis mandibular fracture in 12 years old children using erich arch bar:A case report. Journal of Dentomaxillofacial Science 2(1): 45-48. D01:10.15562/jdmfs.v2i1.456

\section{Introduction}

Mandibular fracture is a major cause of oromaxillofacial injury on child trauma cases. The prevalence of fractures in boys is two times higher than girls. Dentoalveolar injuries occur about $60 \%$ to less than 5 years children although the cases rarely need hospitalization. In pediatric patients, about $40 \%$ fractures involve mandible and about 15 to $20 \%$ fractures of symphysis with the rare involvement of the mandibular ramus.

Oromaxillofacial fracture patterns in children vary in skeletal anatomy and social environmental factors. The general principle in the treatment of mandibular fractures in children and adults is the same, but the selection of the treatment in children depends on the age and the level of tooth development. In addition, maxillofacial fractures treatment in children is also associated with a psychological condition, physiological fracture, growth and anatomical characteristics of children.

The differences in the management of mandibular fractures in children are caused by several considerations, including anatomical variations, speeds healing, patient compliance and the potential for changes in growth and development of the mandible. Treatment becomes more difficult to do on deciduous teeth for the purpose of fixation as roots size is not good enough and can lead to resorption and imperfect eruption in permanent teeth. It is associated with long-term aesthetic and functional rehabilitation of facial as the effects of the injury, so the performed treatment will give a huge influence for subsequent growth.

In pediatric patients, the ability of faster wound healing with fewer complications coupled with good tissue vascularization and blood vessels that supply the face can be an advantage. Additionally, through growth and adaptability processes in children, the damaged orofacial tissue repair and function recovery are better in children than adults.

One of the mandibular fracture treatment types in children is closed reduction using erich arch bar which aims to get the occlusion fixation and bony union.

\section{Case Report}

A 12 year-old pediatric male patient came with a broken lower jaw and was referred to the Department of Oral and Maxillofacial Surgery Emergency Room (ER) at Dr. Hasan Sadikin Hospital. From anamnesis, it was found that the patient had an accident about 2 hours earlier before hospital admission when he was driving a motorcycle at moderate pace in Karawang. Patients wore half face helmet as he had sudden lost of balance thus fell off with falling mechanism of chin hitting the motorcycle handlebar beforehand. After the incident, the patient was conscious. No nausea and 


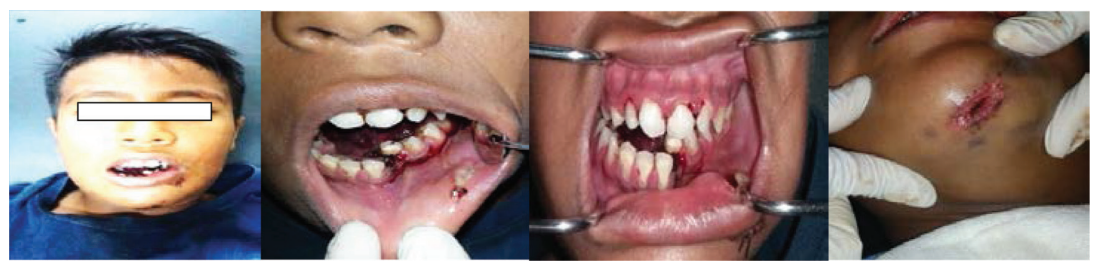

Figure 1 Profile of extra oral and intra oral images

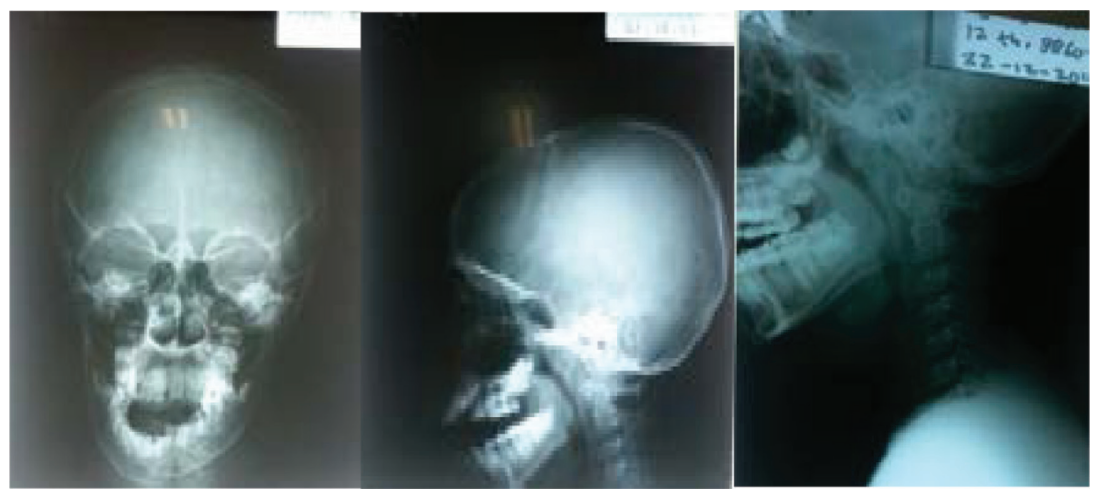

Figure 2 AP head plain, Lateral and servikal radiographs
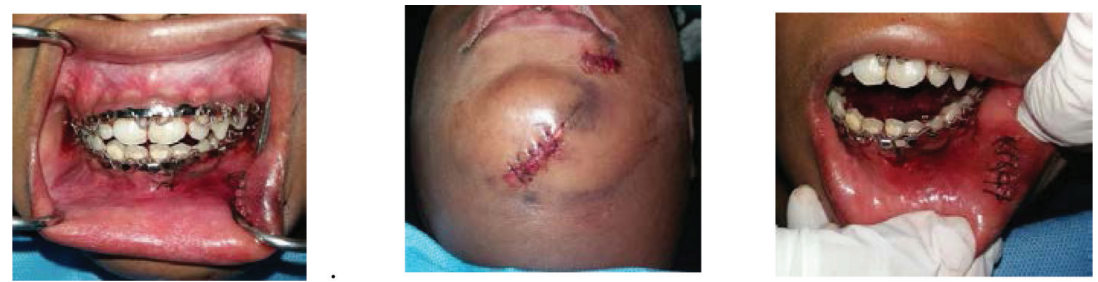

Figure 3 Post IDW, A. Post extra oral suture, B. Post intra oral suture

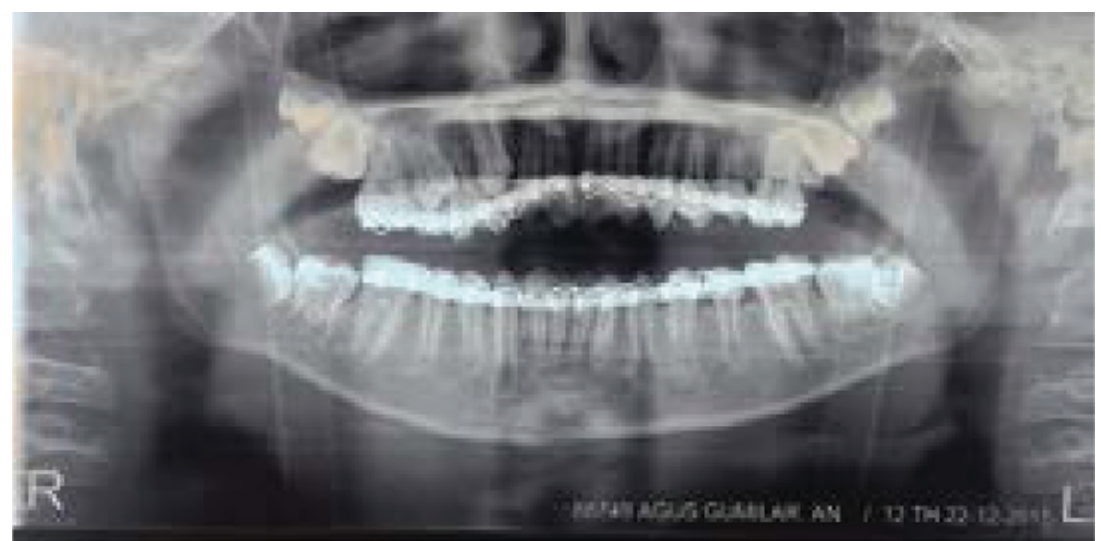

Figure 4 3rd day post IDW panoramic radiograph
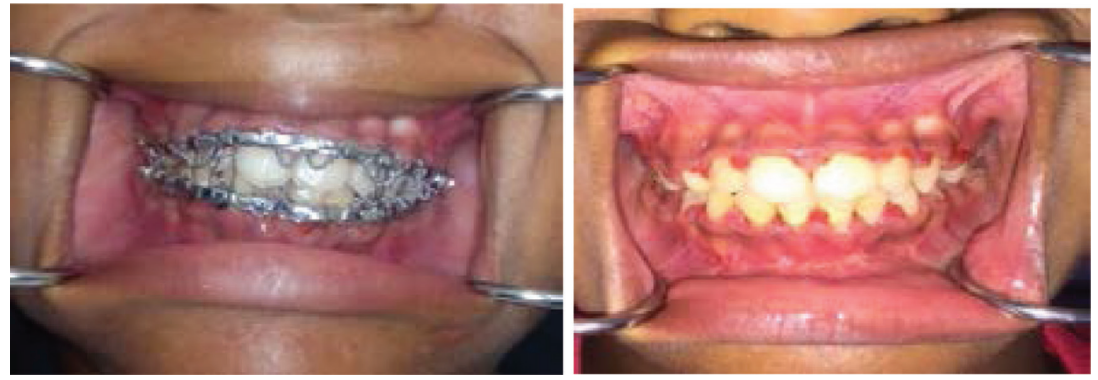

Figure 5 7th day and week 8 control images vomiting were found. From anamnesis, bleeding and fracture on the front of the lower jaw were found figure 1. Patient was then taken to Karawang General Hospital, infusion was installed, stitches in his chin and head x-rays were performed figure 2. He was then referred to the ER at Dr. Hasan Sadikin Hospital, Bandung.

Based on the principles of ATLS, Primary survey was done with findings: A. Clear with C-spine protection, B. symmetrical chest shape and movements, right Vesicular Breath Sound was equal to the left, respiration 18 times per minute, C. Blood pressure $110 / 70 \mathrm{~mm} \mathrm{Hg}$, pulse 78 times per minute, D. with Glascow Coma Scale (GCS15) (E4M6V5) measurements, isochoric pupils with diameter of $3 \mathrm{~mm}$ left equal to right, no light reflex disorder and no parese. Secondary survey was within normal limits.

Extra-oral examination showed facial asymmetry with stitches on the chin with a size of $2 \times$ $0.5 \mathrm{~cm}$ and on the lower lip with a size of $1 \times 0.5 \mathrm{~cm}$ from the previous hospital. Intra-oral examination showed penetrating injuries at the lower lip with a size of $1 \times 0.5 \times 0.3 \mathrm{~cm}$ and the gum region of teeth $31-32$ with a size $1 \times 0.5 \times 0.5 \mathrm{~cm}$ reaching to the underlying bone.

Blood tests showed results within normal range. An emergency action taken was observation of the general state of patients with GCS assessment, and vital signs, the position of the patient's head of 30 degrees, oxygenation with nasal cannula 2-4 liters per minute, infusion of $\mathrm{NaCl} 0.9 \% 1,500 \mathrm{cc}$ per day, and a non-conservative treatment operation. Then it proceeded with the injection of anti-tetanus serum (ATS) and tetanus toxoid (TT), amoxicillin antibiotic of $500 \mathrm{mg}$ IV, ketorolac analgesic of $30 \mathrm{mg}$ and $\mathrm{H} 2$-blockers such as ranitidine of $50 \mathrm{mg}$.

The wound debridement was done using $0.9 \% \mathrm{NaCl}$ mixed with gentamicin, using a ratio of $500 \mathrm{cc}$ of $0.9 \% \mathrm{NaCl}$ mixed with $2 \mathrm{cc}$ gentamicin $(10 \mathrm{mg} / \mathrm{cc})$. Intraoral laceration wound was stitched using silk vicryl 4.0 and 4.0 and the extra oral wound laceration was sutured using nylon 6.0. Fixation was performed using Inter Dental Wiring (IDW) Erich Arch Bar on the upper and lower jaws of teeth 16-26 and 36-46 figure 3. In order to follow the wound progress, panoramic $x$-ray then performed on day three after wiring procedures figure 4. Figure 5 shows the condition of wiring after a week and two months (IDW was removed).

\section{Discussion}

Mandibular fractures in children that commonly occurred in the hospital are the face and head fracture. The numbers of cases in boys are two times higher than in girls where the fractures are generally 
caused by falls, blunt trauma and motorcycle accidents. High prevalence of mandible regions affected in children are the condyles, sub condyles and angulus (80\%). Symphysis or parasymphysis is only affected $15-20 \%$, while the ramus is rare affected region.

Factors that should be considered to determine the definitive therapy include age and patient cooperation, the duration between trauma and treatment, location or expansion of the area of injury, involvement of primary teeth or permanent, stage of root development, a fracture in the alveolar bone and the health of periodontal tissue on the teeth involved.

Management of oromaxillofacial emergency trauma patients should receive immediate attention in the respiratory tract, adequacy of ventilation, control internal and external bleeding. ${ }^{1,89}$ Primary survey assessment (ABCDE) is a priority therapy based on vital signs and mechanism of injury, life-threatening situation quickly recognized and resuscitation immediately performed. A preliminary analysis of all trauma patients is conducted based on Advance Trauma Life Support (ATLS) of the American College of Surgeons (ACS). ${ }^{6,8,9}$

Examination of the airway in the patient in this case revealed a clear airway with $\mathrm{C}$-Spine protection. If intra oral bleeding occurs, suctioning is done immediately so the airway is not interfered and obstruction can be prevented. Attempt to free the airway is done by keeping the airway away from intra oral bleeding and protecting the cervical spine. ${ }^{6,8,9}$

Breathing, ventilation and oxygenation given by nasal cannula 2-4 liters per minute, good ventilation covering the good function of the lungs, chest wall and diaphragm are given. Each of these components was evaluated quickly. Circulation with $0.9 \% \mathrm{NaCl}$ infusion of 20 drops per minute maintenance was done to keep the patient's hemodynamic situation stable and complete blood count and blood clotting factors were simultaneously performed. Three clinical findings that in seconds can provide information on the patient's hemodynamic state are the level of awareness, skin color and pulse. ${ }^{6,8,9}$ External bleeding cannot be found in these patients.

Disability and neurologic status in these patients were assessed by (GCS15) (E4M6V5) showing spontaneous eye opening with pupillary size and reactions showed no signs of lateralization, motoric function followed orders and good verbal communication. ${ }^{6,89}$ This patient was fully awake with GCS of 15 .

Secondary examination in this patient survey was carried out by the principle of head-to-toe examination from head to toe, supporting procedures such as radiological and laboratory examination could be done on this occasion. The examinations included anamnesis, extra oral physical examination, head and oromaxillofacial, and intra oral examination which covered the status localist and supporting tissues surrounding the teeth. ${ }^{6,8,9}$ Results of intra-oral examination showed fracture lines at the anterior region of the mandible.

Emergency Management of oral and maxillofacial surgery in these patients include general maintenance of the accompanied complications, a careful clinical examination, $\mathrm{x}$-rays proper interpretation, determination of the type and kind of fracture. Furthermore, the treatment of soft and hard tissue injuries was done. Reduction, fixation and immobilization of fractures were performed using inter dental wiring (IDW) erich arch bars. Simultaneous pain management and administration of antibiotics were administered. ${ }^{7.9}$ Administration of prophylactic antibiotics, bed rest with head elevation of 30 degrees were conducted in order to avoid circumstances that could lead to sudden increased intracranial pressure such as coughing, straining and sneezing. ${ }^{4,5}$

Patients with a very young age and the low level of cooperation may complicate the management of post-surgical instructions causing the healing becomes longer. On the other hand, wound healing can be faster because it is supported by the presence of tissue vascularization and a good supply of blood vessels on the face. Moreover, with the process of growth and adaptability in children, repair of the damaged tissue and recovery of orofacial function in children are better than in the adults. ${ }^{9}$

Fractures with minimal displacement of bone in children can be treated with several technique variations, namely Tape Muzzles, circumferential wiring, acrylic splint, percutaneous skeletal fixation, open reduction, resorbable plates, orthodontic resins, modified orthodontic brackets, rubber elastics in combination with orthodontic and nickel titanium staples. In fractures with severe shifting, treatment options can vary from intermaxillary fixation, cap splints to coat with mini plate or resorbable plate. ${ }^{9 \cdot 11}$

Oromaxillofacial fracture treatment with anatomical reduction combined with adequate stabilization aims to obtain bony union. Healing and unification of bone fracture or injury occurs through several processes, A. The inflammatory phase with the invasion of neutrophils and macrophages, B. Osteoinduction, ie cellsprecursor cells in endosteum: periosteum and surrounding tissues become osteoblasts followed by osteocon-duction, which the osteoblast entering the fracture area, $\mathrm{C}$. The formation of callus which contains fibroblasts, osteoblasts and cells-other cells, D. Chondroblasts produce the 
basic substance, the fibroblasts produce collagen and osteoblasts produce hydroxyapatite, E. Bone apposition and endochondral ossification, F. The formation of callus which consist of unorganized woven bone, followed by osteoclasts and osteoblasts remodeling into lamellar bone, G. Then, fracture is stiffly fixed and reduced, less callus formation and endochon-dral ossification, healing then proceeds mainly with apposition, $\mathrm{H}$. After the remodeling is complete, structure of healed bone is the same with normal bone without scarring of the bone. ${ }^{9}$

Management of mandibular symphysis fracture in this case occur in a child with perfectly erupted permanent teeth except for tooth 15 . The advantage of treatment with erich arch bar in this case is the support of adequate permanent dentition as anchoring accompanied with the development stage of roots that is almost complete, good periodontal tissues and the process of growth and adaptability in children. Therefore, the repair of orofacial damaged tissue and the recovery of its function in this case can give good results. ${ }^{10,11}$

Metabolic management in children after surgery is more complex than in adults. Special attention should be given to the calories, fluids and electrolytes management, as well as blood transfusions. Management of comprehensive pediatric patient after oral and maxillofacial surgery is very important for better patient healing. ${ }^{10,11}$

\section{Conclusion}

Emergency management of oromaxillofacial trauma in the emergency room needs special attention, precise treatment and quick action. Management of mandibular symphysis fracture in children aged of 12 years old with the perfectly erupted permanent teeth using erich arch bar provides a good healing results.

\section{Conflict of Interest}

The authors report no conflict of interest

\section{References}

1. Pedersen GW. Buku ajar praktis bedah mulut. Jakarta: EGC; 1996.

2. Zollman FS. Manual of traumatic brain injury management. New York: Demos Medical; 2011. p. 25-31.

3. Satyanegara. Ilmu bedah saraf. 5 th ed. Jakarta: Gramedia Pustaka Utama; 2014. p. 322.

4. Greenberg MS. Handbook of neurosurgery 7 th ed. Canada: Thieme; 2010. p. 297-306.

5. Francis BQ, Quinn MS, Fractures BS. Grand rounds presentation the University of Texas medical branch in galves-ton. J Otolaryngol 2013: 1-7.

6. Cedera kepala dalam american college of surgeon. Advance trauma life support. USA: First Impression; 1997. p. 196-235.

7. Engin DA, Solakoglu AG, Komut E, et al. Assessment of maxillofacial trauma in emergency department. World J Emerg Surg 2014;9: 1-7.

8. Booth PW, Eppley B, Schmelzeisen R. Maxillofacial trauma and esthetic facial reconstruction. 2nd ed. Saunders; 2013. p. 28-58.

9. Raymond JF. Oral and maxillofacial trauma. 4th ed. St. Louis Missouri: Saunders; 2013. p. 2.

10. Vellore, Krishna. Circummandibular wiring of symphisis fracture in a five year old child. Case report in dentistry. Hindawi: Publishing Corporatio; 2013.

11. Sharma, Sunli. Pediatric Mandibular fracture : A Review. IJCPD 2009;2: 1-5.

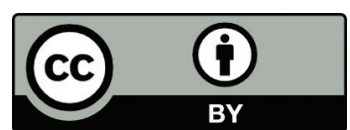

This work is licensed under a Creative Commons Attribution 